\title{
PERAN KELUARGA DALAM MEMBERI PEMAHAMAN MENGENAI KESETARAAN GENDER KEPADA ANAK
}

Karlina

Institut Agama Kristen Negeri Toraja

$\underline{\text { Karlina100401@gmail.com }}$

Abstract : The View that men have more roles or responsibilities than women is something that is difficult to change until now. this paper aims to chage the wrong views in the family and society regarding gender equality. this can be started from giving the corret understanding to children trought simple things in family.

Keywords : Family, Gender equality, Children

Abstrak : Pandangan yang mengatakan bahwa laki-laki lebih memiliki peran atau tanggungjawab yang lebih besar dibandingkan perempuan, menjadi sesuatu yang sulit di ubah hingga saat ini. Tulisan ini bertujuan agar persepsi atau pandangan yang salah dalam keluarga maupun masyarakat mengenai Kesetaraan Gender dapat berubah. Hal ini dapat dimulai dari memberi pemahaman yang benar kepada anak melalui hal yang sederhana dalam keluarga.

Kata Kunci : Keluarga, Kesetaraan Gender, Anak.

\section{PENDAHULUAN}

Anak adalah anugerah dalam setiap keluarga yang harus disyukuri. dalam hal ini orang tua akan memberikan cinta kasihnya kepada anak, baik dalam mengasuh dan mendidik, peran orang tua sangat penting disini termasuk dalam pembentukan karakter seorang anak. Dalam Alkitab anak sangat berharga dimata Yesus dalam kitab Injil Lukas 18:19 dikatakan bahwa Yesus memandang anak sangat berharga, dan mengatakan bahwa jangan mengahalang-halangi mereka (Anak) sebab orang-orang seperti inilah yang empunya kerajaan Allah.

Namun kadang kala orang tua yang memiliki anak perempuan menganggap bahwa mereka memiliki tanggungjawab yang lebih besar dari pada memiliki anak laki-laki. dalam kehidupan sosial kadangkala perempuan sering dipandang sebelah mata. kebanyakan orang menganggap bahwa perempuan tidak mampu melakukan sesuatu. seolah bahwa perempuan adalah makhluk 
yang paling lemah. Padahal kita hidup di zaman dimana seharusnya perempuan adalah makhluk yang setara dengan laki-laki. namun nyatanya bahwa masih banyak orang beranggapan bahwa perempuan itu tidak harus punya pendidikan yang tinggi, karena tugas mereka hanyalah di dapur,mengurus anak dan rumah tangga. Dan kadang pula orang mengatakan bahwa hanya lakilaki yang boleh bekerja atau mencari nafkah sedangkan perempuan tidak dan ini banyak terjadi dalam masyarakat.

\section{TUJUAN DAN MANFAAT}

Tulisan ini bertujuan dan bermanfaat untuk memberi pemahaman kepada Orang Tua atau keluarga memahami sepenuhnya peran mereka dalam hal memberi pemahaman atau pandangan mengenai kesetaraan Gender yang benar mengenai kesetaraan Gender pada Anak Dan Perempuan tidak lagi di pandang sebelah mata dan Agar orang tua menyadari peran mereka dalam memberi pemahaman yang benar mengenai kesetaraan Gender pada Anak yang dapat dimulai dari hal-hal kecil yang dilakukan dalam Keluarga.

\section{PEMBAHASAN}

\section{Pengertian Anak dan Keluarga}

Pengertian anak secara Etimologi merujuk Kamus Umum Bahasa Indonesia diartikan sebagai manusia yang masih kecil ataupun manusia yang belum dewasa. ${ }^{1}$ Sedangkan Keluarga adalah sekumpulan orang yang di hubungkan oleh perkawinan, adopsi dan kelahiran yang bertujuan menciptakan dan mempertahankan budaya yang umum, meningkatkan perkembangan fisik, mental, emosional dan social dari individu-individu yang ada di dalamnya terlihat dari pola interaksi yang saling ketergantungan untuk mencapai tujuan bersama. Keluarga merupakan bagian dari manusia yang setiap hari berhubungan dengan kita. ${ }^{2}$ Anak dalam sebuah keluarga merupakan suatu Anugerah yang seharusnya di syukuri dimana keluarga dan anak merupakan dua hal yang tidak dapat dipisahkan satu dengan yang lainnya,Anak dalam keluarga harus di kasihi dan dipandang berharga. Allah sendiri menunjukkan betapa berharganya seorang Anak yaitu Yesus Kristus. seperti Allah Bapa mengasihi Anak-anaknya demikian pula orang tua harus mengasihi aak-anaknya, Hal tersebut dapat dinyatakan oleh orangtua dalam perbuatan nyata maupun dengan pernyataan kasih melalui tutur kata, teladan perbuatan baik orangtua akan meneguhkan bahwa ia

\footnotetext{
${ }^{1}$ W. J. S. Poerwadarminta, Kamus umum Bahasa Indonesia, Ed. 3 (Jakarta: Balai Pustaka, 2003).

${ }^{2}$ Suprajitno, Asuhan Keperawatan Keluarga: Aplikasi Dalam Praktik, edisi 1 (Jakarta: Penerbit Buku Kedokteran EGC, 2004), 1.
} 
disayangi dan diperhatikan. sedangkan nasehat atau saran lewat kata-kata yang indah dari orangtua akan menumbuhkan kebijaksanaan dalam diri anak ${ }^{3}$

\section{Kesetaraan Gender dan pandangan Alkitab}

Kesetaraan Gender (Gender Equality) adalah suatu konsep yang menyatakan bahwa lakilaki dan perempuan memiliki kebebasan untuk mengembangkan kemampuan personal mereka dan membuat pilihan-pilihan tanpa pembatasan oleh seperangkat stereotype, prasangka, dan peran yang kaku. Gender berasal dari bahasa inggris, secara etimologi artinya jenis kelamin. Gender menurut terminologi adalah suatu konsep kultur/budaya yang berusaha untuk membuat perbedaan dalam hal peran, perilaku, mentalitas, dan karakteristik antara laki-laki dan perempuan dalam menentukan karakteristiknya. ${ }^{4}$ Gender merupakan identitas yang didapat dalam proses bersosialisasi dengan lingkungan masyarakat. konsep gender membedakan laki-laki dan perempuan secara kultural/budaya dimana laki-laki dianggap rasional, kuat, kekar, dan pemberani, sementara perempuan emosional, cantik, lemah-lembut, dan keibuan. dari pandangan inilah perempuan seringkali dipandang sebelah mata dan tidak mampu melakukan sesuatu dan laki-laki mempunyai tanggung jawab yang lebih besar. Lingkungan masyarakat tradisional sampai sekarang, cenderung melihat status lebih rendah daripada laki-laki. kaum perempuan disebut orang lemah dalam segala hal, sedangkan laki-laki adalah orang yang kuat serta memiliki kelebihan yang luar biasa. ${ }^{5}$ pengaruh dari lingkungan mengenai pendapat ini juga sangat berpengaruh pada anak hingga saat ini, Hal tersebut tampak nyata ketika seorang anak bermain dengan teman-temannya anak perempuan seringkali tidak diikutkan bermain Karena menurut mereka itu bukan permainan perempuan atau bahkan ketika anak perempuan bermain boneka atau bermasak anak laki-laki tidak diikutkan karena merupakan permainan anak perempuan saja. tanpa sadar hal ini terjadi karena pengaruh lingkungan yang sangat besar yang tidak menerima kesetaraan Gender.

\section{Peran Keluarga dalam pembentukan pemahaman tentang kesetaraan Gender}

\footnotetext{
${ }^{3}$ Rannu Sanderan, "EXEMPLARY, MENEMUKENALI KUNCI PENDIDIKAN IMAN BAGI ANAK DALAM KELUARGA DAN PEMBELAJARAN AGAMA DI SEKOLAH,” preprint (Open Science Framework, 19 November 2021), https://doi.org/10.31219/osf.io/bmtrk.

${ }^{4}$ Yunardi Kristian Zega, "Perspektif Alkitab Tentang Kesetaraan Gender dan Implikasinya Bagi Pendidikan Agama Kristen," Didache: Journal of Christian Education 2 (2021), https://doi.org/10.46445/djce.v2i2.431.

5 Rannu Sanderan, "JABATAN GEREJAWI DAN PERAN PEREMPUAN DALAM PELAYANAN GEREJA," preprint (Open Science Framework, 26 November 2021), https://doi.org/10.31219/osf.io/jtcag.
} 
Keluarga secara khusus orang tua memiliki peran yang sangat besar dalam memberi pemahaman yang benar tentang kesetaraan Gender. Namun kebanyakan yang terjadi saat ini adalah hal yang sebaliknya, orang tua lebih sering mengajarkan kepada anak khususnya perempuan bahwa setinggi apapun pendidikan seorang perempuan tetapi nantinya tetap akan kembali pada perannya hanya menjadi seorang ibu rumah tangga yang hanya mengurus anak. begitupun pada anak laki-laki cenderung orang tua akan memberikan lebih banyak tanggungjawab yang besar karena menurut mereka tugas laki-laki adalah bekerja keras unntuk kebutuhan hidup nantinya. Hal ini tentu saja sesuatu yang salah, seharusnya orang tua memberikan pemahaman yang baik kepada anak bahwa tidak adalagi perbedaan strata antara laki-laki dan perempuan. hal ini dapat dimulai dari hal-hal yang kecil yang dapat dilakukan oleh orang tua misalnya saja pekerjaan-pekerjaan rumah yang simple bukan hanya diberikan kepada perempuan namun juga dapat dikerjakan oleh anak laki-laki, misalnya saja menyapu, mencuci piring, mencuci pakaian dan lain sebagainya. Cara sederhana lain yang dapat dilakukan oleh orang tua adalah terlebih dahulu memberi teladan tentang kesetaraan Gender, ketika orang tua terlebih dahulu sudah melakukannya maka secara tidak langsung anak-anak juga akan mengikutinya jangan sampai orangtua yang seharusnya memberi pemahaman yang benar justru tidak melakukannya. Penerapan disiplin dalam diri seorang anak sesungguhnya merupakan pola pendidikan Exemplaris (Metamodel); dimana sang anak sendiri akan menirukan pola disiplin yang sama pada keturunannya atau generasi pelanjutnya kelak. ${ }^{6}$ Dengan melihat hal yang dilakukan oleh orangtuanya anak pun akan mengikutinya, dikatakan bahwa otak manusia lebih banyak bekerja melalui gambar (Visualisasi) atau apa yang dilihat, bagi anak yang memiliki kemampuan Visual, maka sesungguhnya bagi tipe anak seperti itu sudah mendapat tempat dan pemolaan dengan demikian anak bisa terlatih untuk memiliki keterampilan mengamati suatu fenomena atau sebuah fakta. ${ }^{7}$ juga dikatakan bahwa Orangtua diberi tanggungjawab mendidik dan otoritas korektif terhadap anaknya, serta seyogianya memberi latihan-latihan pada waktu yang tepat. menurut Amsal Salomo, kebencian orangtua pada anak terlihat pada pembiaran yang tidak memberi koreksi terhadap kesalahan anak (bandingkan kisah Eli dan kedua Anaknya $)^{8}$ Hal lain yang dapat juga dilakukan oleh orang tua adalah tidak

\footnotetext{
6 Sanderan, "EXEMPLARY, MENEMUKENALI KUNCI PENDIDIKAN IMAN BAGI ANAK DALAM KELUARGA DAN PEMBELAJARAN AGAMA DI SEKOLAH."

${ }^{7}$ Rannu Sanderan, "Heuristika dalam Pendidikan Karakter Manusia Toraja Tradisional," BIA': Jurnal Teologi dan Pendidikan Kristen Kontekstual 3, no. 2 (19 Desember 2020): 306-27, https://doi.org/10.34307/b.v3i2.213.

8 Rannu Sanderan, "Disiplin Asketisme dan Harmoni Kontribusi Disiplin Diri bagi Pengembangan Pendidikan Kristen,” preprint (Open Science Framework, 28 November 2021), https://doi.org/10.31219/osf.io/frsnz.
} 
membatasi anak dalam memberi pendapat baik anak perempuan maupun laki-laki dan tidak harus pendapat Laki-laki yang selalunya di dengarkan. umat beragama yang berbeda masing-masing diberi kesempatan untuk berbicara dan mendengar dalam kapasitas yang setara dan sejajar serta dalam kesadaran bahwa masing-masing pihak mengungkapkan kebenaran yang patut untuk dipertimbangkan. ${ }^{9}$

\section{KESIMPULAN DAN SARAN}

Kesetaraan Gender adalah sesuatu yang sangat diperlukan pada saat ini, namun nyatanya hal itu belum dapat dilakukan dengan sepenuhnya, hal ini dikarenakan pemahaman yang salah mengenai Strata atau peran Gender dalam sebuah keluarga maupun lingkungan sekitar. karena itu sangat perlu pemberian pemahaman bagi anak mengenai hal ini dan tentunya peran orang tua dalam keluarga sangat diperlukan, hal ini dapat dilakukan melalui hal-hal yang kecil dan sederhana yang dimulai dari keluarga dimana anak bertumbuh.

\section{DAFTAR PUSTAKA}

Poerwadarminta, W. J. S. Kamus umum Bahasa Indonesia. Ed. 3. Jakarta: Balai Pustaka, 2003. Sanderan, Rannu. "Disiplin Asketisme dan Harmoni Kontribusi Disiplin Diri bagi Pengembangan Pendidikan Kristen.” Preprint. Open Science Framework, 28 November 2021. https://doi.org/10.31219/osf.io/frsnz.

—. "EXEMPLARY, MENEMUKENALI KUNCI PENDIDIKAN IMAN BAGI ANAK DALAM KELUARGA DAN PEMBELAJARAN AGAMA DI SEKOLAH.” Preprint. Open Science Framework, 19 November 2021. https://doi.org/10.31219/osf.io/bmtrk. . "Heuristika dalam Pendidikan Karakter Manusia Toraja Tradisional." BIA': Jurnal Teologi dan Pendidikan Kristen Kontekstual 3, no. 2 (19 Desember 2020): 306-27. https://doi.org/10.34307/b.v3i2.213.

. "INTUISI: Pendalaman Gagasan Hans-George Gadamer tentang Intuisi sebagai Supralogika.” Jurnal Ilmiah Religiosity Entity Humanity (JIREH) 2, no. 2 (23 Desember 2020): 114-25. https://doi.org/10.37364/jireh.v2i2.39.

—. "JABATAN GEREJAWI DAN PERAN PEREMPUAN DALAM PELAYANAN GEREJA.” Preprint. Open Science Framework, 26 November 2021. https://doi.org/10.31219/osf.io/jtcag.

Suprajitno. Asuhan Keperawatan Keluarga : Aplikasi Dalam Praktik. Edisi 1. Jakarta: Penerbit Buku Kedokteran EGC, 2004.

Zega, Yunardi Kristian. "Perspektif Alkitab Tentang Kesetaraan Gender dan Implikasinya Bagi Pendidikan Agama Kristen.” Didache: Journal of Christian Education 2 (2021). https://doi.org/10.46445/djce.v2i2.431.

\footnotetext{
${ }^{9}$ Rannu Sanderan, "INTUISI: Pendalaman Gagasan Hans-George Gadamer tentang Intuisi sebagai Supralogika," Jurnal Ilmiah Religiosity Entity Humanity (JIREH) 2, no. 2 (23 Desember 2020): 114-25, https://doi.org/10.37364/jireh.v2i2.39.
} 
